\title{
Polymeric Micelles and their Properties
}

\section{Rajesh R Wakaskar*}

Research and Development, Insys Therapeutics, Inc. Chandler AZ, USA

Keywords: Polymeric micelles; Nanotechnology; Bioavailability

\section{Introduction}

In recent years, polymeric micelles have attracted a lot of attention in terms of their specific delivery of hydrophobic cargo to the target site. Polymeric micelles are considered more stable than their surfactant counterparts and can prolong circulation times in vivo and their specific accumulation in the tumoral tissues [1]. They can effectively solubilize small hydrophobic drugs in their inner most hydrophobic core while their outer hydrophilic shell can afford protection against any kind of scavenging by the mononuclear phagocytic system [2]. Micelles often display a great resemblance in their comparison to viruses or lipoproteins as carriers of required payload, whether it is DNA for viruses or hydrophobic drugs for lipoproteins [3]. However, both lipoproteins and viruses have their own limitations in delivering their respective payloads to the target sites. Lipoproteins have a greater propensity of being recognized by healthy cells too apart from competing with natural lipoproteins on tumor sites [4]. Viral carriers can be recognized by immune systems, which in turn can elicit an immune response. In contrast, polymeric micelles do afford significant advantages over the above mentioned two carriers in terms of delivery of a hydrophobic payload. Physical stability and chemical stability in plasma, however, still remain the major concerns for polymeric micelles [5].

\section{Micellar Structure}

Polymeric micelles are characterized by a robust core-shell structure. Diblock copolymers have been known to self-assemble into dynamic micellar structures, with a hydrophilic shell (representing one block) and a hydrophobic core (representing the other block) [6,7]. Similarly, tri or multi block copolymers with a poly(ethylene oxide)poly(propylene oxide)-poly(ethylene oxide) (PEO-PPO-PEO) have been known to self-assemble into micelles with the polyethylene oxide (PEO) portion representing the hydrophilic shell and polypropylene oxide (PPO) portion representing the hydrophobic core $[8,9]$. These micelles are very dynamic in their assembly and are generally formed in water above a certain concentration, which is also known as the critical micellar concentration (CMC) [10].

\section{Applications}

The important mechanisms that are generally employed to release the payload at the target sites are active and passive targeting. Passive targeting is reliant on the disease pathology and certain specific properties on the delivery system in order for preferential accumulation of the drug at the region of interest [11]. This process is famously described as the Enhanced Permeation and retention effect, as championed by Dr. Maeda et al $[12,13]$. Maeda and colleagues first described this EPR effect in murine solid tumor models. Later, this effect was corroborated by other scientists. Manifold higher concentrations of the drugs can be seen in the tumors when these drugs are administered as polymer-drug conjugates or when they are encapsulated in the polymer. This phenomenon can be extended to inflammation and infection too [14]. Some of the common approaches for passive targeting involve stimuli-specific release of the drug at target sites. For example: the $\mathrm{pH}$ around the tumor region (hypoxic) is generally around 5. So if $\mathrm{pH}$ sensitive polymers are incorporated, then there will be a significant difference in the tumoral accumulation of drugs, as opposed to using a non $\mathrm{pH}$-sensitive polymer $[15,16]$. Active targeting utilizes an approach, which involves surface modification of the nanocarrier systems, such as an attachment of a targeting ligand which is ultimately directed to certain receptors that will be over expressed in certain pathological systems [17]. One of the classic examples is the over expression of folate receptors in certain rapidly proliferating tumor cells. In such instances, the surface of nanocarrier is aptly modified with folic acid, which will serve as the targeting ligand in this case.

\section{Advantages and Disadvantages of Micellar Systems}

Polymeric micelles can be safely used for parenteral administration than conventional solubilizing agents such as polyethoxylated Castor oil (Cremophor EL) or polysorbate $80[18,19]$. Being kinetically stable, polymeric micelles dissociate very slowly, thus prolonging the circulation times in blood. Their cores are typicallylarger than surfactant micelles thus improving their capacity to solubilize hydrophobic drugs [20]. When these polymeric micelles are coupled with Polyethylene glycol (PEG), they are conferred "Stealth" properties, thus reducing their uptake by the macrophages of the reticulo-endothelial (RES) system, and in turn, extending their in vivo circulation times. Some of the polymeric micelles are modulated to overcome the drug-efflux or resistance by inhibiting P-Glycoprotein (PGP) transport or MultiDrug Resistance Protein 2 (MDRP 2) transport [21]. In spite of these, micellar delivery is prone to some short-comings too. Dilution of these micelles, when injected intravenously, may shift the equilibrium towards the unimer state, thus leading to their dissociation. This dissociation may be accelerated when these unimeric components bind to other constituents such as proteins [22]. This phenomenon can be overcome by cross-linking the micelles, either through covalent core cross-linking $[23,24]$ or through shell cross-linking, thus affording rigidity to the micellar structure [25].

\section{Conclusion}

Generally, more than $50 \%$ of the drugs possess, inherently, very limited water solubilities [21]. So, different nanotechnological methods have been generally employed to improve upon their

${ }^{*}$ Corresponding author: Rajesh R Wakaskar, Research and Development, Insys Therapeutics, Inc. Chandler AZ, USA, Tel: 480-656-9020; E-mail: rajesh20w@ gmail.com

Received: February 15, 2017; Accepted: March 24, 2017; Published: March 31 2017

Citation: Wakaskar RR (2017) Polymeric Micelles and their Properties. J Nanomed Nanotechnol 8: 433. doi: 10.4172/2157-7439.1000433

Copyright: ( 2017 Wakaskar RR. This is an open-access article distributed under the terms of the Creative Commons Attribution License, which permits unrestricted use, distribution, and reproduction in any medium, provided the original author and source are credited. 
solubility characteristics, which in turn can subsequently improve their bioavailabilities too. One of the most desired techniques is to load these extremely insoluble drugs into polymeric micelles or even conjugate these drugs to the polymers by covalent linking. These block copolymers have gained attention due to a number of favorable characteristics such as their easy commercial availability, varied compositions that can be further easily tailored, negligent or no side effects, proven compatibility with other excipients [26]. On the other hand, they also suffer from certain limitations such as their tendency to aggregate and their limited stability in vivo. Thus, these polymeric micelles are a subject of greater interest currently, and more investigative studies are being dedicated to have a better understanding of their overall characteristics [27].

\section{References}

1. Jones M, Leroux J (1999) Polymeric micelles - a new generation of colloida drug carriers. European journal of pharmaceutics and biopharmaceutics: official journal of Arbeitsgemeinschaft fur Pharmazeutische Verfahrenstechnik e. 48: 101-111.

2. Kwon GS, Okano T (1996) Polymeric micelles as new drug carriers. Advanced Drug Delivery Reviews 21: 107-116.

3. Kazunori K, Masayuki Y, Teruo O, Yasuhisa S (1993) Block copolymer micelles as vehicles for drug delivery. Journal of Controlled Release 24: 119-132.

4. Firestone RA (1994) Low-density lipoprotein as a vehicle for targeting antitumor compounds to cancer cells. Bioconjugate chemistry 5: 105-113.

5. Jones MC, Leroux JC (1999) Polymeric micelles-a new generation of colloidal drug carriers. European Journal of pharmaceutics and biopharmaceutics 48 : 101-111.

6. Mochida Y, Cabral H, Kataoka K (2017) Polymeric Micelles for Targeted Tumor Therapy of Platinum Anticancer Drugs. Expert Opinion on Drug Delivery 23: 1-16.

7. Vaishya RD, Gokulgandhi M, Patel S, Minocha M, Mitra AK (2014) Novel dexamethasone-loaded nanomicelles for the intermediate and posterior segment uveitis. AAPS PharmSciTech 15: 1238-1251.

8. Prasad KN, Luong TT, FlorenceJoelle Paris AT, Puisieux F (1979) Surface activity and association of ABA polyoxyethylene-polyoxypropylene block copolymers in aqueous solution. Journal of Colloid and Interface science 69: 225-232.

9. Kabanov AV (1989) The neuroleptic activity of haloperidol increases afte its solubilization in surfactant micelles: micelles as microcontainers for drug targeting. FEBS letters 258: 343-345.

10. Vaishya RD, Khurana V, Patel S, Mitra AK (2014) Controlled ocular drug delivery with nanomicelles. Wiley interdisciplinary reviews. Nanomedicine and Nanobiotechnology 6: 422-437.

11. Ganta S, Devalapally H, Shahiwala A, Amiji M (2008) A review of stimuliresponsive nanocarriers for drug and gene delivery. Journal of Controlled Release 126: 187-204

12. Maeda H, Matsumura $Y$ (1988) Tumoritropic and lymphotropic principles of macromolecular drugs. Critical reviews in therapeutic drug carrier systems 6 193-210.

13. Nor Ohtsuka M, Miyauchi $Y$ (1987) Anticancer effects of arterial administration of the anticancer agent SMANCS with lipiodol on metastatic lymph nodes. Cancer 59: 1560-1565.

14. van Vlerken LE, Duan Z, Seiden MV, Amiji MM (2007) Modulation of intracellular ceramide using polymeric nanoparticles to overcome multidrug resistance in cancer. Cancer research 67: 4843-4850.

15. Shenoy D, Little S, Langer R, Amiji M (2005) Poly (ethylene oxide)-modified poly ( $\beta$-amino ester) nanoparticles as a $\mathrm{pH}$-sensitive system for tumor-targeted delivery of hydrophobic drugs: part 2. In vivo distribution and tumor localization studies. Pharmaceutical research 22: 2107-2114.

16. Shenoy DB, Amiji MM (20005) Poly (ethylene oxide)-modified poly ( $\varepsilon$-caprolactone) nanoparticles for targeted delivery of tamoxifen in breast cancer. International journal of pharmaceutics 293: 261-270.

17. Wagner E (2007) Programmed drug delivery: nanosystems for tumor targeting. Expert Opinion on Biological Therapy 7: 587-593.

18. Le Garrec D, Gori S, Luo L, Lessard D, Smith DC, et al. (2004) Poly ( $\mathrm{N}$-vinylpyrrolidone)-block-poly (D, L-lactide) as a new polymeric solubilizer for hydrophobic anticancer drugs: in vitro and in vivo evaluation. Journal of Controlled Release 99: 83-101.

19. Strickley RG (2004) Solubilizing excipients in oral and injectable formulations Pharmaceutical research 21: 201-230.

20. Kwon GS (2003) Polymeric micelles for delivery of poorly water-soluble compounds. Critical Reviews ${ }^{\mathrm{TM}}$ in Therapeutic Drug Carrier Systems.

21. Chiappetta DA, Sosnik A (2007) Poly (ethylene oxide)-poly (propylene oxide) block copolymer micelles as drug delivery agents: improved hydrosolubility, stability and bioavailability of drugs. European Journal of Pharmaceutics and Biopharmaceutics 66: 303-317.

22. van Nostrum CF (2011) Covalently cross-linked amphiphilic block copolymer micelles. Soft Matter 7: 3246-3259.

23. Bontha S, Kabanov AV, Bronich TK (2006) Polymer micelles with cross-linked ionic cores for delivery of anticancer drugs. Journal of controlled release 114 : 163-174.

24. Kim JO, Kabanov AV, Bronich TK (2009) Polymer micelles with cross-linked polyanion core for delivery of a cationic drug doxorubicin. Journal of Controlled Release 138: 197-204.

25. Wakaskar RR, Bathena SP, Tallapaka SB, Ambardekar VV, Gautam N, et al. (2015) Peripherally cross-linking the shell of core-shell polymer micelles decreases premature release of physically loaded combretastatin A4 in whole blood and increases its mean residence time and subsequent potency against primary murine breast tumors after IV administration. Pharmaceutical research 32: 1028-1044.

26. Varun K, Patel S, Agrahari V, Mitra AK (2014) Novel pentablock copolymer based nanoparticles containing pazopanib: a potential therapy for ocular neovascularization. Recent Patents on Nanomedicine 4.1: 57-68.

27. Ambardekar, Vishakha V (2013) The efficacy of nuclease-resistant CholsiRNA in primary breast tumors following complexation with PLL-PEG (5K) Biomaterials 34: 4839-4848. 